\title{
Evaluating the cement stabilization of arsenic-bearing iron wastes from drinking water treatment
}

Tara M. Clancya†, Kathryn V. Snydera, Raghav Reddya, Antonio Lanzirottib, Susan E. Amrosec, Lutgarde Raskina, Kim F. Hayesa*

aDepartment of Civil \& Environmental Engineering, University of Michigan, Ann Arbor, MI 48109 bCenter for Advanced Radiation Sources, University of Chicago, Chicago, IL 60637

cDepartment of Civil \& Environmental Engineering, University of California at Berkeley, Berkeley, CA 94720

\footnotetext{
*corresponding author, telephone: (734)764-8495, fax: (734)763-2275, email:ford@umich.edu †current affiliation: Soil and Crop Sciences, Cornell University, Ithaca, NY 14853
} 


\section{Abstract}

Cement stabilization of arsenic-bearing wastes is recommended to limit arsenic release from wastes following disposal. Such stabilization has been demonstrated to reduce the arsenic concentration in the Toxicity Characteristic Leaching Procedure (TCLP), which regulates landfill disposal of arsenic waste. However, few studies have evaluated leaching from actual wastes under conditions similar to ultimate disposal environments. In this study, land disposal in areas where flooding is likely was simulated to test arsenic release from cement stabilized arsenic-bearing iron oxide wastes. After 406 days submersed in chemically simulated rainwater, $<0.4 \%$ of total arsenic was leached, which was comparable to the amount leached during the TCLP $(<0.3 \%)$. Short-term (18 h) modified TCLP tests ( $\mathrm{pH} 3-12)$ found that cement stabilization lowered arsenic leaching at high $\mathrm{pH}$, but increased leaching at $\mathrm{pH}<4.2$ compared to non-stabilized wastes. Presenting the first characterization of cement stabilized waste using $\mu \mathrm{XRF}$, these results revealed the majority of arsenic in cement stabilized waste remained associated with iron. This distribution of arsenic differed from previous observations of arsenic-calcium solid phases when arsenic salts were stabilized with cement, illustrating that the initial waste form influences the stabilized form. Overall, cement stabilization is effective for arsenic-bearing wastes when acidic conditions can be avoided.

Key words: arsenic, cement stabilization, Toxicity Characteristic Leaching Procedure 


\section{Highlights}

- Cement stabilization minimized leaching from actual arsenic-bearing iron waste

- $<0.4 \%$ total As leached from cement stabilized waste over 406 days in rainwater

- Leaching in rainwater was similar to that predicted by the TCLP $(<0.3 \%)$

- As leaching during the TCLP and modified-TCLP tests was highly dependent on pH

- $\mu \mathrm{XRF}$ shows As remains largely associated with Fe after cement stabilization of waste

- At $\mathrm{pH}>4.2$ cement stabilization is expected to limit arsenic release

\section{Introduction}

Worldwide contamination of drinking water by arsenic has spurred the development and implementation of numerous arsenic-removal technologies, many of which rely on the sorption of arsenic to oxidized iron solids [1-6]. The resulting arsenic-bearing iron solid waste can become a new source of arsenic contamination depending on the disposal environment. This is of concern in developed or developing countries where waste solids from technologies used to remove arsenic from drinking water are commonly disposed in either landfills or soil environments near filtration facilities, respectively. Landfill conditions may cause the release of arsenic from ferric iron solids through reductive dissolution and changes in $\mathrm{pH}[7,8]$. However, non-landfill disposal is common in developing countries, but has not been well characterized. For example, in Bangladesh regulations require disposal of wastes in concrete-lined pits, although in practice pits can drain directly into nearby ponds or soils [9].

To minimize the potential for release, arsenic-bearing wastes have been mixed with cement for disposal [10-12]. Cement stabilization includes mixtures of cement, water, and sand that are used to create mortars and if aggregates, such as crushed gravel or stone are included, the resulting material is a concrete. While the effectiveness of cement stabilization has been shown to vary widely based on both waste and concrete characteristics $[13,14]$, studies have found that cement or lime addition typically reduces arsenic measured in the leachate of the Toxicity Characteristic Leaching Procedure (TCLP) [15-19] and other leaching tests included in the Leaching Environmental Assessment Framework (LEAF) [20] when compared to non-stabilized wastes. The TCLP is frequently used to measure leaching potential and is the test applied by the US E.P.A. to determine if wastes are safe for municipal solid waste landfill disposal or must be treated as a hazardous waste [21].

The leachant solution for the TCLP is comprised of acetic acid ( $\mathrm{pK}_{\mathrm{a}}$ of $4.75,25^{\circ} \mathrm{C}$ ), and is typically designed to result in a $\mathrm{pH}<5$, though the final $\mathrm{pH}$ of the test is not always reported, and can vary depending on the alkalinity of the waste tested. For a typical TCLP formulation, the testing of cement- or lime-stabilized waste can result in $\mathrm{pH}>5$, which may confound the interpretation of the leaching results. In studies measuring the leaching of arsenic from cement stabilized arsenic 

lower leaching $[17,22]$.

Few studies have evaluated arsenic leaching from cement stabilized wastes over long time periods ( $>24$ hours) $[23,24]$, yet such studies are warranted to assess their true stability in disposal environments. Sanchez et al. [23] evaluated the leaching of arsenic, added as a salt, from a mortar under environments with varied relative humidity and $\mathrm{CO}_{2}$ levels and found arsenic release continued over 94 days regardless of conditions. Singh and Pant [24] similarly observed continuous leaching from cement stabilized arsenite adsorbed to activated alumina over a 90 period. More information linking the effectiveness of short-term leaching tests for predicting longer term leaching under actual disposal conditions is needed to assess whether short-term leaching tests can be used to predict the ultimate arsenic release over the much longer exposure periods expected in common disposal environments.

When cement stabilized arsenic wastes are stored near treatment plants or used in nonload bearing structural elements, rainwater is expected to be the natural leachant. In South Asia, the potential for flooding may be especially high during the monsoon seasons [25]. While the TLCP (with acetic acid) is expected to provide a more aggressive leaching condition than rainwater, it remains to be demonstrated whether the standard short-term TLCP test is a good predictor of the efficacy of cement stabilized waste for keeping arsenic from leaching over long periods of rainwater exposure.

The stability of arsenic in cement stabilized wastes depends on the type of solid phases that bind arsenic within the cement. Characterization of cement and lime stabilized arsenic by bulk Xray diffraction (XRD) has identified crystalline arsenic calcium phases, including: $\mathrm{NaCaAsO}_{4} \cdot 7 \cdot 5 \mathrm{H}_{2} \mathrm{O}, \mathrm{Ca}_{4}(\mathrm{OH})_{2}\left(\mathrm{AsO}_{4}\right)_{2} \cdot 4 \mathrm{H}_{2} \mathrm{O}, \mathrm{Ca}_{3}\left(\mathrm{AsO}_{4}\right)_{2} \cdot 3{ }^{2 / 3} \mathrm{H}_{2} \mathrm{O}, \mathrm{Ca}_{5}\left(\mathrm{AsO}_{4}\right)_{3}(\mathrm{OH})[15,16,26]$. However, in most cases, these calcium-arsenic solids originated from arsenic salts and therefore may not be representative of those that form from arsenic drinking water treatment wastes in which arsenic is typically sorbed to iron solids. In the only studies characterizing cement or lime stabilization of arsenic sorbed to iron solids, calcium arsenic solids were observed by FTIR [17] and the calcium iron arsenic solid, yukonite $\left(\mathrm{Ca}_{2} \mathrm{Fe}_{3}\left(\mathrm{AsO}_{4}\right)_{4}(\mathrm{OH}) \cdot 12 \mathrm{H}_{2} \mathrm{O}\right)$ was found by XRD [19]. Since bulk XRD detection is limited to crystalline solids, if amorphous phases are present, XRD would not identify arsenic associated with these phases. Similarly, other techniques such as bulk X-ray absorption spectroscopy can be difficult to interpret when samples contain multiple phases. These challenges require the application of new techniques to determine the distribution of arsenic from iron-based drinking water treatment in cement stabilized solids.

In this study, wastes from a pilot-scale iron electrocoagulation system operated for arsenic removal from a contaminated groundwater source in West Bengal, India [27] were used to: (i) 
evaluate leaching from cement stabilized wastes over long-term exposure to simulated rainwater, (ii) compare long-term simulated leaching with short-term leaching tests, and (iii) characterize the distribution of arsenic in cement stabilized wastes using $\mu \mathrm{XRF}$ and crystalline phases using $\mu \mathrm{XRD}$. These results are used to assess the potential for cement stabilization arsenic waste to provide long term stability against leaching under representative disposal conditions, to determine if short term leaching test are effective predictors of this stability, and to identify the arsenic solid phase associations responsible for its stability against leaching. These results can inform the disposal of other arsenic-bearing iron oxide wastes commonly generated during drinking water treatment.

\section{Experimental}

\subsection{Mortar preparation and waste characteristics}

The cement stabilization of arsenic-bearing wastes was performed by creating a mortar through the hand mixing a combination of ordinary Portland cement, sand, and water at a ratio of 1:3:0.5 by mass $[17,28]$. An iron oxide arsenic-bearing waste from a pilot scale Electro-Chemical Arsenic Remediation (ECAR) unit operating in West Bengal, India [27] was dried at $105^{\circ} \mathrm{C}$ and incorporated into the mortar at either $1 \%$ or $3 \%$ of the total mass, replacing some of the sand. The arsenic and iron coordination environments in wastes from similar systems have been extensively characterized $[4,29]$. Wet mortar was poured into plastic molds to create $0.83 \mathrm{~cm}^{3}$ cubes. Molds were sealed with plastic wrap and cured for 48 hours before cubes were removed from the molds. Cubes were then stored in plastic bags and inside an anaerobic glove box to reduce exposure to carbon dioxide before use in leaching tests. To compare the impact of curing conditions, another set of $2.05 \mathrm{~cm}^{3}$ cubes was prepared using three different curing conditions. One set, as described above, was cured for 48 hours wrapped in plastic. Two other sets were prepared and cured in water for a total curing time of either 6 days or 28 days. Cubes from all conditions were removed from molds after 48 hours.

\subsection{Long-term rainwater leaching tests}

Leaching tests were performed by exposing uncrushed mortar cubes to rainwater for 406 days to simulate long-term leaching. Synthetic rainwater was made based on an average major ion concentrations measured in rainwater samples collected in areas surrounding Dhaka, Bangladesh [30](Error! Reference source not found.). 100 mortar cubes containing 1\% ECAR waste were placed into each of three glass containers with $300 \mathrm{~mL}$ of the synthetic rainwater. Liquid samples were collected and filtered through $0.2 \mu$ m nylon filters. The liquid volume removed at various sampling times was replaced with an equivalent volume of synthetic rainwater. Dionized water, typically less than $10 \mathrm{~mL}$ per week, was added to replace water loss due to evaporation to maintain a constant volume. Triplicate experiments were also set-up with containers holding 100 mortar cubes and filled with $300 \mathrm{~mL}$ of synthetic rainwater for 1 hour daily after which the rainwater was 
drained and a sample collected. For the remaining 23 hours the cubes would be left to air dry. This process was continued for 70 days. After the $\mathrm{pH}$ was measured (Mettler Toledo, Columbus, $\mathrm{OH}$ ), the samples were acidified with nitric acid for the measurement of total arsenic, iron, and calcium using inductively-couple plasma mass spectroscopy (ICP-MS) (PerkinElmer ALEN DRC-e, Waltham, MA). The detection limit for arsenic was $1.1 \mu \mathrm{g} / \mathrm{L}$. The instrument error was $5 \%$, as determined by the variation from known standards. The minimum measurement error was $0.8 \mu \mathrm{g} / \mathrm{L}$. Errors are reported as the highest of the standard deviation between replicate samples, the instrumental error, or the minimum measurement error.

\subsection{Short-term leaching: TCLP and modified TCLP}

For short-term leaching tests, the TCLP was performed as outlined by the U.S. EPA [21]. Briefly, $0.1 \mathrm{M}$ acetic acid was used as the leachant with an initial $\mathrm{pH}$ of either $2.88 \mathrm{or} \mathrm{pH} 4.93$, adjusted with $1 \mathrm{M} \mathrm{NaOH}$. In modified TCLP tests, the acetic acid concentration was varied $(0.1 \mathrm{M}$, 1.5 M, $3 \mathrm{M}, 4.5 \mathrm{M}$, and $6 \mathrm{M}$ ) to change the final leachate $\mathrm{pH}$. In TCLP tests, the leachant to solid ratio was 20:1 and was typically performed with $1 \mathrm{~g}$ of dried and crushed mortar or raw waste in a 50 $\mathrm{mL}$ centrifuge tube. Replicate samples, between three and five, were mixed by using an end-overend sample tube rotator for 18 hours. Samples were filtered through $0.7 \mu \mathrm{m}$ pre-washed glass microfiber filters (EMD Millipore, Darmstadt, Germany) and acidified with nitric acid for total arsenic measurement via ICP-MS.

Short-term leaching tests to compare leaching from differentially cured mortars were performed using uncrushed $2.05 \mathrm{~cm}^{3}$ mortar cubes. Three curing conditions tested included: 2 day curing wrapped in plastic, 6 day curing in water, and 28 day curing in water. For each of these curing conditions five replicate leaching tests were conducted at three different acetic acid concentrations, $0.1 \mathrm{M}, 1.5 \mathrm{M}$, and $3 \mathrm{M}$. Each replicate test was performed with one cube and $40 \mathrm{~mL}$ of leachant. The percentage of arsenic leached from each cube was calculated based on total digestions of mortar cubes from the same batch of mortar and the mass of the dry cubes before the leaching test. Cubes were placed into the leaching solution inside of $50 \mathrm{~mL}$ centrifuge tubes and were mixed on a shaker plate for 18 hours before samples were filtered and acidified for total arsenic measurement via ICP-MS.

\subsection{Short-term leaching: NaOH Leaching}

To assess the leaching of raw ECAR waste at high $\mathrm{pH}$, a short-term leaching test in $0.1 \mathrm{M}$ $\mathrm{NaOH}$ was performed, where $0.01 \mathrm{~g}$ of dried ECAR waste was added to $40 \mathrm{~mL}$ of leachant and rotated in an end-over-end rotator for either 1 or 3 days. This was also repeated in a12 $\mathrm{mM} \mathrm{CaO}$ solution to evaluate whether the presence of calcium impacted the results. Samples were filtered and acidified as described above.

\subsection{Total digestions}


Total digestions were performed on the waste and mortar solids according to the US EPA Method 3050B to determine total solid arsenic concentrations [31]. Between 0.5 and $1.0 \mathrm{~g}$ of dried and crushed solids from a subset of at least five cubes or a sample of ECAR waste were treated with $10 \mathrm{~mL}$ of $7.8 \mathrm{M}$ nitric acid and incubated at $100^{\circ} \mathrm{C}$ for 2 hours followed by the addition of hydrogen peroxide, typically $1 \mathrm{~mL}$, or until vigorous bubbling stopped, and then incubated for another 2 hours at $100^{\circ} \mathrm{C}$. Cooled samples were filtered through Whatman no. 41(GE Healthcare Life Sciences, Pittsburg, PA) filter paper, diluted, and acidified with nitric acid for total arsenic measurement by ICP-MS.

\subsection{Solids characterization}

Samples of 1\% ECAR waste mortar cubes taken prior to rainwater incubation and on day 386 of rainwater leaching were prepared for X-ray microprobe analysis at beamline 13-ID-E, Sector 13 GeoSoilEnviroCARS, Advanced Photon Source at Argonne National Laboratory [32]. Polished thin sections $(30 \mu \mathrm{m})$ of the mortar cubes were prepared on quartz glass slides by Spectrum Petrographics (Vancouver, WA) using vacuum embedding with Epotek 301 and processing as water and heat sensitive. Microfocused X-ray fluorescence ( $\mu \mathrm{XRF}$ ) compositional mapping was performed using a monochromatic X-ray beam focused to a spot size of $1 \times 2 \mu \mathrm{m}(\mathrm{V} \times \mathrm{H})$ using a pair of $200 \mathrm{~mm}$ long, elliptically-bent, Rh-coated silicon mirrors in a Kirkpatrick-Baez geometry. X-ray fluorescence spectra were collected using a 4-element Vortex-ME4 silicon-drift-diode detector (Hitachi, Tokyo, Japan) coupled to XMap digital spectrometers (XIA, Hayward, CA). Maps were collected in a continuous scan mode using incident X-ray energy of $13.0 \mathrm{keV}$, a pixel size of $2 \mu \mathrm{m}$, and a scan rate of $30 \mathrm{msec} / \mathrm{pixel}$. The energy dispersive detector was filtered using $230 \mu \mathrm{m}$ of Kapton film to minimize calcium $\mathrm{K}$ fluorescence. This reduced detector dead time and pile up. XRF energy dispersive maps were processed using beamline specific software (http://gsecars.uchicago.edu). Elemental mass ratios of selected areas with a range of arsenic intensities were calculated using the NRLXRF program [33] using a standardless fundamental parameters approach [34], referenced to measured Ca Ka emission intensities and assuming a calcite bulk chemical composition. Corrections for fluorescent X-ray absorption by the sample, detector-sample air path, and to account for kapton filtering of the detector (used to lower detector dead time from Ca K-alpha fluorescence) were used in calculating the elemental mass. At points of interest, $\mu$ XRD patterns were collected in transmission mode using a Perkin Elmer 16 inch amorphous silicon digital X-ray detector (XRD1621) with incident beam energy of $17.0 \mathrm{keV}$ and a 5 second collection time per frame. FIT2D was used to subtract the background of the quartz slide from all 2D images before integration and calibration using alumina as the standard [35]. Comparisons between 1D integrated patterns and reference materials were performed using MDI Jade 2010 (Livermore, CA). 


\subsection{ECAR Waste and Mortar Characterization}

The total arsenic concentration in the mortar cubes was determined by the total digestion method and found to be $14.6 \pm 2.1$ and $32.7 \pm 1.6 \mu \mathrm{g}$ As/g mortar for $1 \%$ and $3 \%$ ECAR wastes, respectively. The arsenic concentration of the raw ECAR waste was $995 \pm 50 \mu \mathrm{g}$ As/g waste. In order to compare leaching across different solids, the arsenic leached is presented as a percentage of the total arsenic based on these digestions. Other characteristics of similar materials have been previously reported, for the same mortar composition [17] and ECAR waste [4, 29].

\subsection{Long-term rainwater leaching compared to TCLP estimate}

The $\mathrm{pH}$ in the long-term rainwater leaching experiment (406 days) started out at a relatively high $\mathrm{pH}$ of 12.7 , but then gradually decreased to a final $\mathrm{pH}$ of $\sim 8.9$ (Figure 1 ). The high $\mathrm{pH}$ was caused by the dissolution of portlandite $\left(\mathrm{Ca}(\mathrm{OH})_{2}\right)$ from the mortar, which resulted in Ca leaching. Over time calcite precipitation likely occurred, given the exposure of the rainwater to carbon dioxide from the atmosphere. Consistent with this, dissolved calcium concentrations were above $100 \mathrm{mg} / \mathrm{L}$ before day 16, but decreased to below $1 \mathrm{mg} / \mathrm{L}$ after day 29 (data not shown). Iron concentrations were around $1 \mathrm{mg} / \mathrm{L}$, but decreased to below the detection limit $(0.1 \mathrm{mg} / \mathrm{L})$ after day 20 (data not shown). Before day 18, arsenic concentrations in the aqueous phase were below the detection limit $(0.1 \mathrm{ug} / \mathrm{L})$, but began to increase over time, reaching an average concentration of $21 \pm 4.8 \mu \mathrm{g} / \mathrm{L}$ by day 406 among the three replicates. The lag in arsenic release has been observed previously [24] and was likely caused by arsenic sorption/co-precipitation with calcite in the leaching solution [36-39]. After 406 days, the total arsenic leached from the cubes represented about $0.34 \%$ of the total amount of arsenic present in the mortar. In the 70 day experiment, where cubes were exposed to rainwater for 1 hour daily, followed by 23 hours of drying, concentrations of arsenic above the detection limit were not measured. In this test, due to the high volume of rainwater used (300 mL per day), up to $1.45 \%$ of the total arsenic present could have leached without being detected. Taken together, the results from both long-term leaching studies indicate that cement stabilization is very effective in keeping arsenic from leaching by rainwater. 

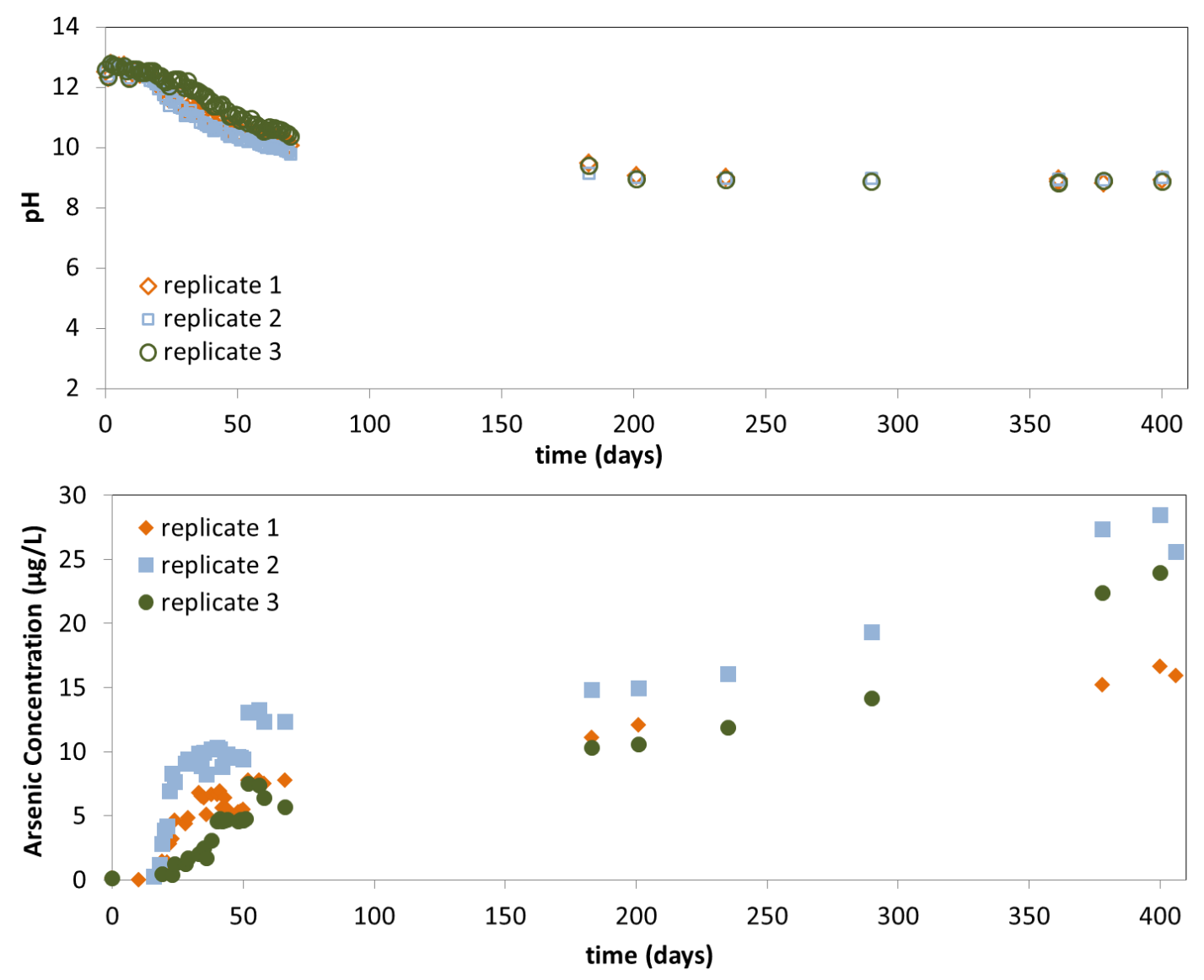

Figure 1. pH (a) and total arsenic (b) in filtered rainwater leachate over time for triplicate incubations of 100 mortar cubes containing 1\% ECAR.

The standard TCLP test, using $0.1 \mathrm{M}$ acetic acid and initial $\mathrm{pH}$ of 2.9 as the leachant, resulted in an average leachate arsenic concentration from cement stabilized waste of $2.0 \pm 0.8 \mu \mathrm{g} / \mathrm{L}$ from triplicate tests. This is far below the limit for disposal in municipal solid waste landfills $(<5,000$ $\mu \mathrm{g} / \mathrm{L}$ ] [21] and consistent with previous reports of leaching from cement stabilized ECAR waste [40]. The final $\mathrm{pH}$ of the test leachate varied between 6.3 and 11.5. This $\mathrm{pH}$ range was the largest among all replicate tests. Possible causes include the physical and chemical heterogeneity of the cement stabilized waste cubes and the small sample size $(1 \mathrm{~g})$ taken for each test. However, as discussed below, this $\mathrm{pH}$ range is not expected to result in large changes in the arsenic leaching. The amount of arsenic leached from the ECAR mortar under this test, represented $0.27 \%$ of the total arsenic present in the mortar. No statistically significant difference was found between the arsenic leached during the long-term rainwater experiment with uncrushed cubes compared with the short-term TCLP on crushed cubes ( $p$-value $>0.1$; Table 1 ). 
Table 1. Comparison of short-term (TCLP) and long-term (rainwater) leaching

\begin{tabular}{lllll|}
\hline Leaching Test & $\begin{array}{l}\text { \% of total arsenic } \\
\text { leached } \\
\text { average } \\
\text { (std. deviation in } \\
\text { percentage points) }\end{array}$ & $\begin{array}{l}\text { time } \\
\text { (days) }\end{array}$ & $\begin{array}{l}\text { initial } \\
\text { leachant } \\
\text { pH }\end{array}$ & $\begin{array}{l}\text { final } \\
\text { leachate } \\
\text { pH }\end{array}$ \\
\hline Long-term Rainwater Leaching & $0.34( \pm 0.1)$ & 406 & 6.2 & 8.9 \\
\hline $\begin{array}{l}\text { Toxicity Characteristic } \\
\text { Leaching Procedure (TCLP) }\end{array}$ & $0.27( \pm 0.1)$ & 0.75 & 2.9 & $6.3-11.5$ \\
\hline
\end{tabular}

\subsection{Short-term leaching tests with varying $\mathrm{pH}$}

While the design of the TCLP is to determine leaching from solids at a pH between 3 and 5 , solids such as cements result in a much higher final $\mathrm{pH}$. To determine arsenic leaching over a wider $\mathrm{pH}$ range, acetic acid concentrations were varied. Results from the leaching test for cement stabilized ECAR waste and raw ECAR waste are shown in Figure 2, where the mass of arsenic leached is plotted as the percentage of the total arsenic in each solid versus the final leachate $\mathrm{pH}$.

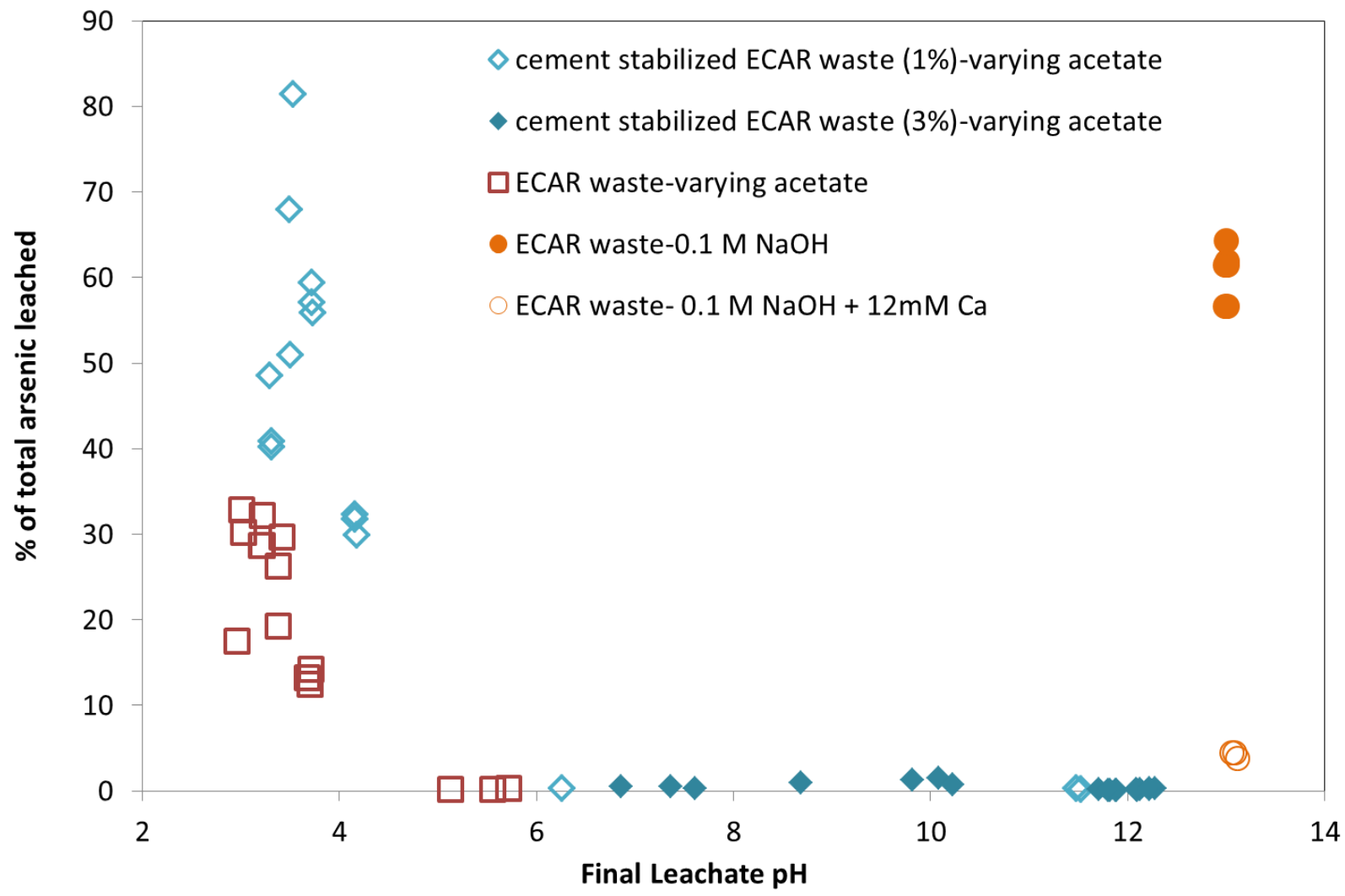

Figure 2. Arsenic leaching versus final leachate pH from short-term leaching tests of ECAR waste with and without cement stabilization. 
When raw ECAR waste was subjected to a high pH environment, i.e. $0.1 \mathrm{M} \mathrm{NaOH}$, up to 64\% of the total arsenic was mobilized. However, in the presence of calcium, the mobilization of arsenic from ECAR waste at high $\mathrm{pH}$ was greatly decreased $(<4 \%)$. This had been previously observed and could be caused by arsenate co-precipitation or sorption to calcite $[19,41]$. A reduction in leaching was also observed when the ECAR is cement stabilized, which resulted in less than $1.5 \%$ mobilization in acetic acid where the final leachate $\mathrm{pH}$ is between 6.2 and 12.3. Given the potential for $\mathrm{Ca}(\mathrm{OH})_{2}$ dissolution from the crushed mortar and the subsequent precipitation of $\mathrm{CaCO}_{3}$ over this $\mathrm{pH}$ range, it is not possible to distinguish between arsenic that remains in its original phase and arsenic that is mobilized and subsequently adsorbed or co-precipitated with calcite. The stability of calcium solids at high $\mathrm{pH}$ is also important in preventing the release of arsenic from the cement stabilized cubes under the long-term rainwater leaching. Leaching from raw ECAR waste was also found to be low as a percentage of the total arsenic present at pH 5.1-5.7. Leachate arsenic concentrations were between 13.4 and $66.2 \mu \mathrm{g} / \mathrm{L}$. This is likely due to the strong sorption of arsenate to iron oxides in the pH range 4-8 [42-44].

At $\mathrm{pH}$ less than 4.2, arsenic mobilization increased with decreasing $\mathrm{pH}$ for both raw ECAR waste and cement stabilized waste. Below this $\mathrm{pH}$, the dissolution of iron oxides would be expected and would result in the release of arsenic. Under these low $\mathrm{pH}$ conditions, slightly more arsenic was leached from the cement stabilized waste than from the raw ECAR waste. Compared to the raw ECAR waste, where lower $\mathrm{pH}$ would increase arsenate sorption, until iron dissolution, cement stabilized wastes may also have some arsenic associated with calcium solids, which could cause more As to leach from the cement stabilized wastes as $\mathrm{pH}$ is lowered and both iron oxides and calcium solids begin to dissolve. These results are consistent with previous reports $[16,17]$, though the increased release from stabilized solids compared to non-stabilized solids at low pH is often overlooked. This is an important consideration for disposal conditions where wastes may be exposed to low $\mathrm{pH}$ solutions, such as acid rain ( $\mathrm{pH} \sim 4.3$ ), animal wastes ( $\mathrm{pH}$ as low as 4) [45], or landfill leachate during early stages of landfill degradation (pH 4.5) [46]. Even though cement stabilization is used as a pre-treatment for landfill disposal [24], the long-term effects of landfill leachate exposure are not well characterized. There is some indication that cement stabilized materials will not dissolve in landfill leachates which are typically oversaturated with respect to calcite $[47,48]$. However, if dissolution of the cement stabilized solids were to occur, the reducing conditions would likely limit re-sorption/co-precipitation of arsenite with calcite [38, 39, 49]. For storage conditions above ground, low $\mathrm{pH}$ and reducing conditions would be less likely, and the $\mathrm{pH}$ inside the cement stabilized solids would remain high, producing conditions where the mortar would remain intact and low arsenic leaching would be expected. Generally, the advantage of cement stabilized waste versus raw ECAR iron waste is due to the maintenance of a high $\mathrm{pH}$ 
condition (Figure 1a) and the encapsulation of the waste which will remain protective until the mortar was dissolved. At low $\mathrm{pH}$ and after the concrete is crushed the protective effects of cement stabilization do not minimize arsenic leaching (Figure 2).

In addition to $\mathrm{pH}$, other variables may affect the leaching from cement stabilized wastes. One factor is curing conditions, which can affect the properties of mortar or concrete. Increased curing times have been associated with increases in compressive strength and decreases in water permeability, carbonation depth, and porosity [50-52]. However, there has been limited research relating these properties with leaching behavior. Previous studies have compared leaching using the TCLP, with a final $\mathrm{pH}$ above 5 , and have found slightly decreased leaching with increased curing time, from 14 to 28 days, and very little change between leaching from samples cured 28 days and samples cured longer than 1 year [15, 53-55]. In this study, we found little difference in curing conditions on arsenic leaching at a final pH 3.8-4.0 (Figure 3). At the lowest final pH, the percentage of the total arsenic leached was greatest for the 6 day water cured samples $(27.6 \% \pm 3.1$ pp), followed by 28 day water cured samples (15.7\% $\pm 1.2 \mathrm{pp})$, and lowest for 2 day plastic wrapped samples $(10.6 \% \pm 1.0 \mathrm{pp})$ (Figure 3$)$. This indicates that the leaching potential for the cubes used in the long-term leaching (which were also cured for 2 days in plastic) may be lower than that from mortars cured in water. Standard lab tests for mortar and concrete are typically performed after water curing, but actual conditions may vary in the field application of cement stabilization for wastes. The differences in leaching observed here warrant further study to determine the optimal curing conditions for field applications. 


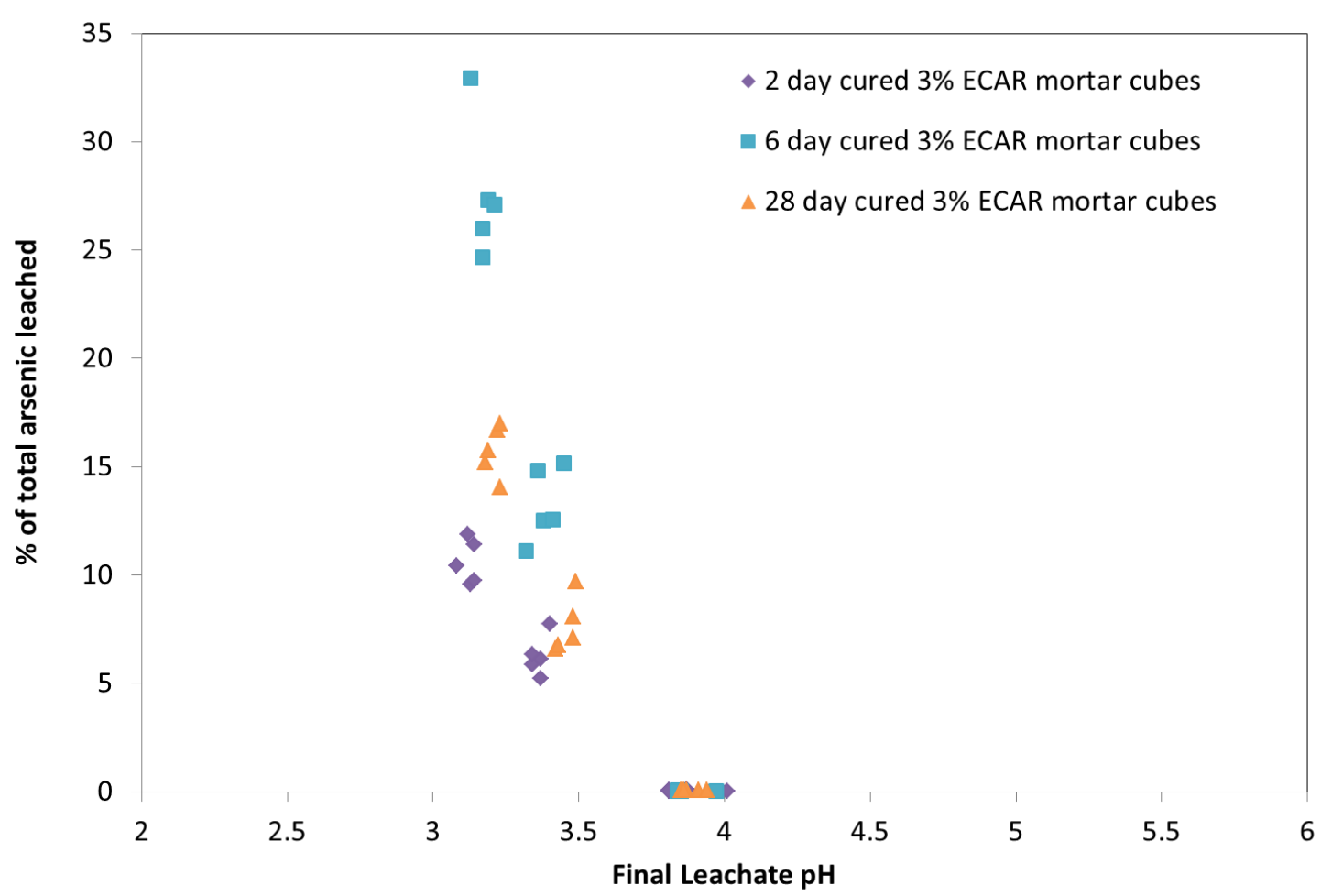

Figure 3. The percent of total arsenic leached from uncrushed mortar cubes containing $3 \%$ ECAR waste in leaching tests with varying concentrations of acetic acid.

\subsection{Solids characterization}

$\mu \mathrm{XRF}$ elemental mapping shows the distribution of calcium, arsenic, and iron in areas near ECAR waste particles within the mortar cube (Figure 4). In maps from both the initial time point and after 386 days in rainwater, arsenic and iron were found together. Calcium was more abundant near the edges of the ECAR waste particle and away from the waste. A linear relationship exists between As and Fe intensities, but not between As and Ca intensities (Error! Reference source not found.). Calculated elemental mass ratios for three areas with a range of arsenic intensities (areas shown in Error! Reference source not found.) show the ratio of Fe to As ranging between 153:1 and 181:1, while Ca to As varies to a greater extent between 59:1 and 668:1. These results highlight that the majority of arsenic present in the cement stabilized waste remains associated with iron, similar to the initial state of the ECAR waste. Of importance is also the areas surrounding the ECAR waste particle with lower arsenic. This may be caused by some desorption of arsenic from the iron under the high $\mathrm{pH}$ conditions of the cement matrix and subsequent association of with calcium phases. This is consistent with the finding that at low $\mathrm{pH}(<4)$ more arsenic leaches under short-term leaching tests from cement stabilized samples compared with raw ECAR waste as a result of the additional arsenic released from the ECAR waste at high $\mathrm{pH}$ while in the cement matrix. These findings are also supported by evidence that arsenic is preferentially associated with 
iron in natural environments and agricultural lime samples, but associated with calcium when iron sorption is limited [56-59].

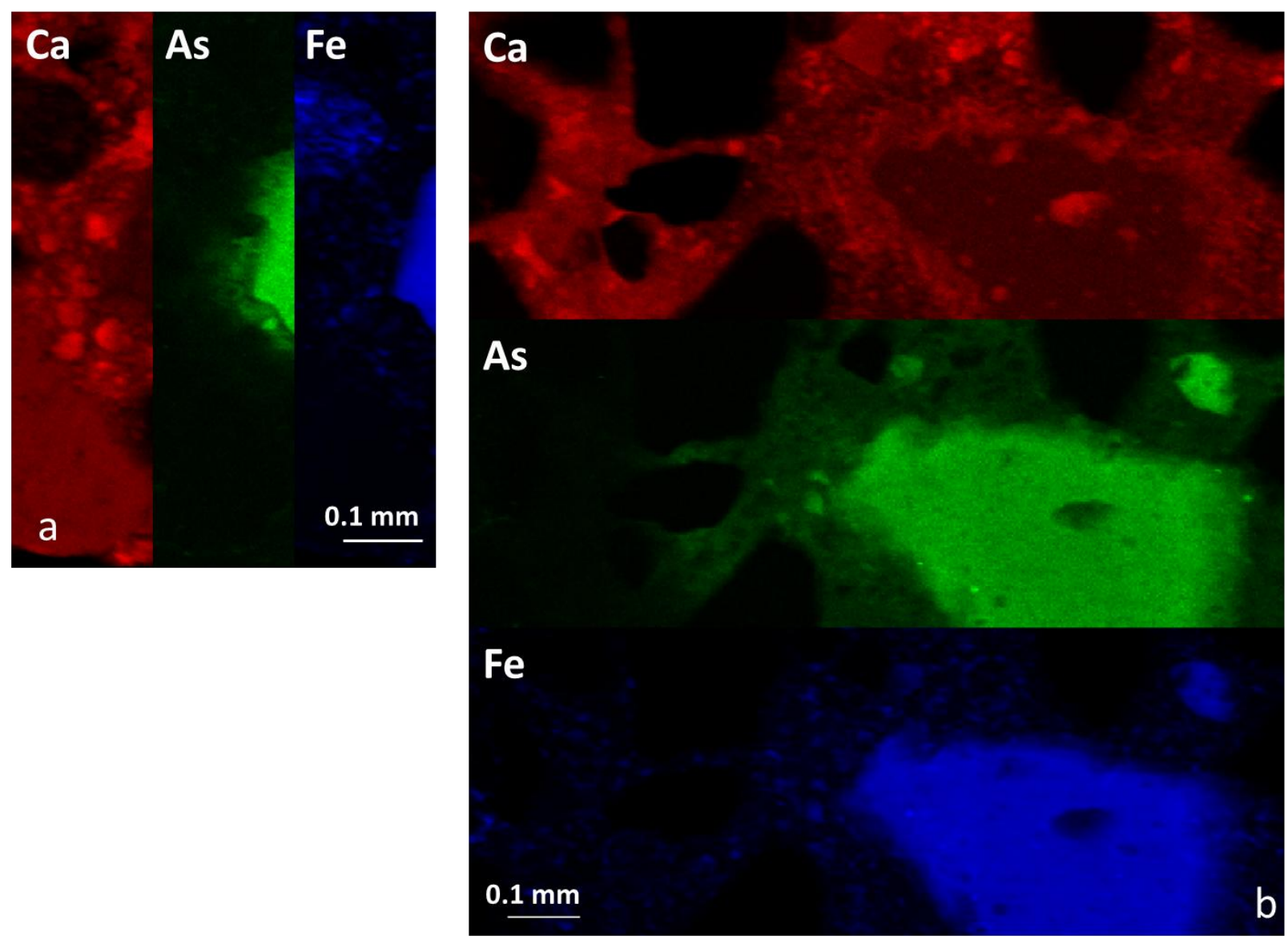

Figure 4. $\mu$ XRF elemental maps of measured calcium (red), arsenic (green), and iron (blue) $X$-ray fluorescence intensities in thin sections of cement stabilized ECAR waste from day 0 before flooding (a) and day 386 of rainwater flooding (b).

$\mu \mathrm{XRD}$ patterns from across the cubes show evidence for calcite, ettringite, portlandite, calcium aluminum iron oxide, dolomite, and calcium silica solids (Figure 5), all phases commonly found in cementitious materials [60-62]. In these samples no evidence for crystalline calcium arsenic phases was found. This is in contrast to studies of cement stabilization with arsenic salts $[15,16,26]$ and is likely due to the use of an iron-based arsenic waste in this study. In one other study of arsenic-bearing iron wastes treated with lime, yukonite was identified using XRD, but was observed only after an accelerated aging performed at $70{ }^{\circ} \mathrm{C}$ for 7 weeks [19]. In a second study of iron wastes, evidence for calcium arsenic phases was found using Fourier transform infrared spectroscopy (FTIR) and X-ray absorption fine structure (EXAFS) [17] though it can be difficult to 
distinguish between arsenic co-precipitated with calcite and calcium arsenic solids, such as johnbaumite, using these techniques $[36,39]$. In this study, $\mu$ EXAFS data was collected, but the signal to noise ratio was too low for quantitative analysis to distinguish between iron or calcium phases. Calcite, although present at day 0, became more abundant in the mortar after long-term incubation (day 386). Calcite was the primary crystalline phase across and around ECAR particles, but there is no evidence for the preferential association of arsenic with calcium phases. 
Figure 5. $\mu \mathrm{XRF}$ compositional maps of mortar from day 0 (a) and day 386 (b) showing the overlay of calcium (red), arsenic (green), and iron (blue), and $\mu$ XRD patterns (c) for points from mortar cubes shown with numbers on the maps for day 0 (top 5 lines) and day 386 (bottom 8 lines).
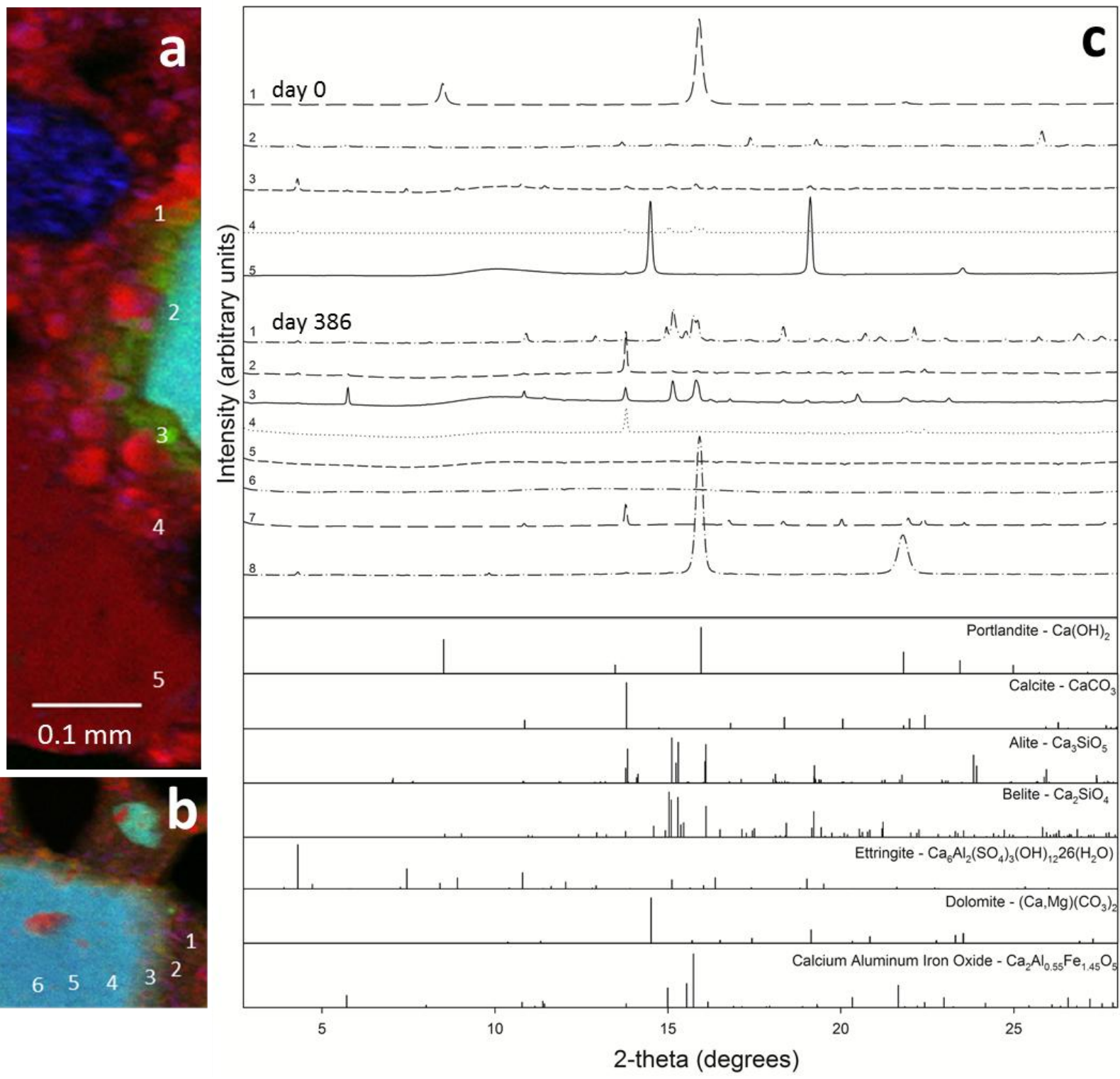


\section{Conclusions}

The results presented here highlight the importance of $\mathrm{pH}$ on the predicted mobility of arsenic from cement stabilized wastes. For long-term exposure of cement stabilized arsenicbearing waste to a simulated rainwater, $\mathrm{pH}$ remained high (>8) and arsenic leaching was low (about $0.34 \%$ of the total arsenic present). This was similar to the amount predicted in the standard TCLP, where the $\mathrm{pH}$ was also high (pH 6.3-11.5). Under short-term leaching conditions with acetic acid, little arsenic was leached between $\mathrm{pH}$ 6.2-12.3. At $\mathrm{pH}<4.2$, increased arsenic leaching was observed from cement stabilized and raw wastes. Characterization of the cement stabilized arsenic-bearing wastes revealed that arsenic was primarily associated with iron, similar to the starting waste material. The primary crystalline phase identified was calcite, but no crystalline calcium arsenic phases were identified, a result that differs from previous studies of cement stabilization with arsenic salts. Taken together, these results indicate that cement stabilization is a promising technique to limit arsenic release into the environment under conditions where exposure to low pH can be avoided. Future studies should further evaluate optimal curing conditions for field applications and the stability of mortar and concrete in other potential disposal environments such as landfills or ponds. 
[1] D. Mohan, C.U. Pittman, Arsenic removal from water/wastewater using adsorbents--A critical review, J. Hazard. Mater., 142 (2007) 1-53.

[2] P. Ravenscroft, H. Brammer, K. Richards, Arsenic pollution: a global synthesis, WileyBlackwell, 2009.

[3] P.R. Kumar, S. Chaudhari, K.C. Khilar, S.P. Mahajan, Removal of arsenic from water by electrocoagulation, Chemosphere, 55 (2004) 1245-1252.

[4] C.M. van Genuchten, S.E.A. Addy, J. Peña, A.J. Gadgil, Removing Arsenic from Synthetic Groundwater with Iron Electrocoagulation: An Fe and As K-Edge EXAFS Study, Environ. Sci. Technol., 46 (2012) 986-994.

[5] A. Neumann, R. Kaegi, A. Voegelin, A. Hussam, A.K.M. Munir, S.J. Hug, Arsenic Removal with Composite Iron Matrix Filters in Bangladesh: A Field and Laboratory Study, Environ. Sci. Technol., (2013).

[6] A.K. Sharma, J.C. Tjell, J.J. Sloth, P.E. Holm, Review of arsenic contamination, exposure through water and food and low cost mitigation options for rural areas, Appl. Geochem., 41 (2014) 11-33.

[7] A. Ghosh, M. Mukiibi, A.E. Sáez, W.P. Ela, Leaching of arsenic from granular ferric hydroxide residuals under mature landfill conditions, Environ. Sci. Technol., 40 (2006) 6070-6075.

[8] M.Y. Stuckman, J.J. Lenhart, H.W. Walker, Abiotic properties of landfill leachate controlling arsenic release from drinking water adsorbents, Water Res., 45 (2011) 47824792.

[9] J.L. Mathieu, A.J. Gadgil, K. Kowolik, S.E.A. Addy, Removing Arsenic from Contaminated Drinking Water in Rural Bangladesh: Recent Fieldwork Results \& Policy Implications, Lawrence Berkeley National Laboratory, (2010).

[10] S. Paria, P.K. Yuet, Solidification-stabilization of organic and inorganic contaminants using portland cement: a literature review, Environ. Rev., 14 (2006) 217-255.

[11] V. Dutre, C. Vandecasteele, Solidification/Stabilisation of Arsenic-Containing Waste: Leach Tests and Behaviour of Arsenic in the Leachate, Waste Manage., 15 (1995) 55-62. [12] M. Leist, R.J. Casey, D. Caridi, The management of arsenic wastes: problems and prospects, J. Hazard. Mater., 76 (2000) 125-138.

[13] M. Leist, R.J. Casey, D. Caridi, The fixation and leaching of cement stabilized arsenic, Waste Manage., 23 (2003) 353-359.

[14] C. Sullivan, M. Tyrer, C.R. Cheeseman, N.J.D. Graham, Disposal of water treatment wastes containing arsenic - a review, Sci. Total Environ., 408 (2010) 1770-1778.

[15] H. Akhter, F.K. Cartledge, A. Roy, M.E. Tittlebaum, Solidification/stabilization of arsenic salts: Effects of long cure times, J. Hazard. Mater., 52 (1997) 247-264.

[16] D.H. Moon, D. Dermatas, N. Menounou, Arsenic immobilization by calcium-arsenic precipitates in lime treated soils, Sci. Total Environ., 330 (2004) 171-185.

[17] C. Jing, G.P. Korfiatis, X. Meng, Immobilization mechanisms of arsenate in iron hydroxide sludge stabilized with cement, Environ. Sci. Technol., 37 (2003) 5050-5056. [18] J. Camacho, H.-Y. Wee, T.A. Kramer, R. Autenrieth, Arsenic stabilization on water treatment residuals by calcium addition, J. Hazard. Mater., 165 (2009) 599-603. [19] Y. Jia, G.P. Demopoulos, Coprecipitation of arsenate with iron(III) in aqueous sulfate media: Effect of time, lime as base and co-ions on arsenic retention, Water Res., 42 (2008) 661-668. 
[20] D.S. Kosson, A.C. Garrabrants, R. DeLapp, H.A. van der Sloot, pH-dependent leaching of constituents of potential concern from concrete materials containing coal combustion fly ash, Chemosphere, 103 (2014) 140-147.

[21] U.S. EPA, Method 1311 Toxicity Characteristic Leaching Procedure, in, 1992, pp. 1-35. [22] I.-H. Yoon, D.H. Moon, K.-W. Kim, K.-Y. Lee, J.-H. Lee, M.G. Kim, Mechanism for the stabilization/solidification of arsenic-contaminated soils with Portland cement and cement kiln dust, Journal of Environmental Management, 91 (2010) 2322-2328.

[23] F. Sanchez, C. Gervais, A.C. Garrabrantsa, R.C. Barna, D.S. Kosson, Leaching of inorganic contaminants from cement-based waste materials as a result of carbonation during intermittent wetting, Waste Manage., 22 (2002) 249-260.

[24] T.S. Singh, K.K. Pant, Solidification/stabilization of arsenic containing solid wastes using portland cement, fly ash and polymeric materials, J. Hazard. Mater., 131 (2006) 2936.

[25] S. Shahid, Rainfall variability and the trends of wet and dry periods in Bangladesh, International Journal of Climatology, 30 (2010) 2299-2313.

[26] J.V. Bothe Jr, P.W. Brown, Arsenic immobilization by calcium arsenate formation, Environ. Sci. Technol., 33 (1999) 3806-3811.

[27] S.E. Amrose, S.R.S. Bandaru, C. Delaire, C.M. van Genuchten, A. Dutta, A. DebSarkar, C. Orr, J. Roy, A. Das, A.J. Gadgil, Electro-chemical arsenic remediation: Field trials in West Bengal, Sci. Total Environ., 488-489 (2014) 539-546.

[28] T. Sugiyama, S. Takahashi, S. Honda, E. Sakai, Current State of the JSCE Standard on Test Method for Leaching of Trace Elements from Hardened Concrete, in: R.N. Kraus, T.R. Naik, P. Claisse, P. Sadeghi (Eds.), 2007.

[29] C.M. van Genuchten, J. Peña, S.E. Amrose, A.J. Gadgil, Structure of Fe(III) precipitates generated by the electrolytic dissolution of $\mathrm{Fe}(0)$ in the presence of groundwater ions, Geochim. Cosmochim. Acta, 127 (2014) 285-304.

[30] D.A. Hadi, M. Billah, K.F. Biswas, I. Rafiqul, A study on chemical composition of atmospheric precipitation at Savar, Joydevpur, Tongi and Narayanganj, Bangladesh, Water, Air, Soil Pollut., 111 (1999) 377-384.

[31] U.S. EPA, Method 3050B Acid Digestion of Sediments, Sludges, and Soils, in: Test Methods for Evaluating Solid Waste, Physical/Chemical Methods SW-846, 1992.

[32] S.R. Sutton, P.M. Bertsch, M. Newville, M. Rivers, A. Lanzirotti, P. Eng, Microfluorescence and microtomography analyses of heterogeneous earth and environmental materials, in: P.A. Fenter, M.L. Rivers, N.C. Sturchio, S.R. Sutton (Eds.) Reviews in Mineralogy \& Geochemistry: Applications of Synchrotron Radiation in LowTemperature Geochemistry \& Environmental Science, Mineral Soc Am, Chantilly, VA, 2002, pp. 429-483.

[33] J.W. Criss, L.S. Birks, J.V. Gilfrich, Versatile x-ray analysis program combining fundamental parameters and empirical coefficients, Analytical Chemistry, 50 (1978) 33-37. [34] B. Kanngießer, Quantification procedures in micro X-ray fluorescence analysis, Spectrochimica Acta Part B: Atomic Spectroscopy, 58 (2003) 609-614. [35] A.P. Hammersley, FIT2D: an Introduction and Overview; Internal Report ESRF97HA02, in, ESRF, Grenoble, France, 1997.

[36] V.G. Alexandratos, E.J. Elzinga, R.J. Reeder, Arsenate uptake by calcite: Macroscopic and spectroscopic characterization of adsorption and incorporation mechanisms, Geochim. Cosmochim. Acta, 71 (2007) 4172-4187. 
[37] M. Lee, I.S. Paik, I. Kim, H. Kang, S. Lee, Remediation of heavy metal contaminated groundwater originated from abandoned mine using lime and calcium carbonate, J. Hazard. Mater., 144 (2007) 208-214.

[38] H.U. Sø, D. Postma, R. Jakobsen, F. Larsen, Sorption and desorption of arsenate and arsenite on calcite, Geochim. Cosmochim. Acta, 72 (2008) 5871-5884.

[39] Y. Yokoyama, K. Tanaka, Y. Takahashi, Differences in the immobilization of arsenite and arsenate by calcite, Geochim. Cosmochim. Acta, 91 (2012) 202-219.

[40] S. Amrose, A. Gadgil, V. Srinivasan, K. Kowolik, M. Muller, J. Huang, R. Kostecki, Arsenic removal from groundwater using iron electrocoagulation: Effect of charge dosage rate, J. Environ. Sci. Health, Part A, 48 (2013) 1019-1030. [41] J.L. Parks, J. Novak, M. MacPhee, C. Itle, M. Edwards, Effect of Ca on As release from ferric and alum residuals, American Water Works Association. Journal, 95 (2003) 108. [42] C. Fuller, J. Davis, G. Waychunas, Surface chemistry of ferrihydrite: Part 2. Kinetics of arsenate adsorption and coprecipitation, Geochim. Cosmochim. Acta, 57 (1993) 2271-2282. [43] S. Dixit, J.G. Hering, Comparison of arsenic(V) and arsenic(III) sorption onto iron oxide minerals: implications for arsenic mobility, Environ. Sci. Technol., 37 (2003) 4182-4189. [44] H.-Y. Wee, T. Kramer, A., Characterization of Arsenic-Containing Water Treatment Residuals, in: Advances in Arsenic Research, American Chemical Society, 2005, pp. 321332.

[45] A. Bertron, J. Duchesne, G. Escadeillas, Attack of cement pastes exposed to organic acids in manure, Cement and Concrete Composites, 27 (2005) 898-909. [46] P. Kjeldsen, M. Barlaz, A. Rooker, A. Baun, A. Ledin, T. Christensen, Present and LongTerm Composition of MSW Landfill Leachate: A Review, Crit. Rev. Environ. Sci. Technol., 32 (2002) 297-336.

[47] D.A.C. Manning, Calcite precipitation in landfills: an essential product of waste stabilization, Mineral. Mag., 65 (2001) 603-610.

[48] P.J. Bennett, F.J. Longstaffe, R.K. Rowe, The stability of dolomite in landfill leachatecollection systems, Canadian Geotechnical Journal, 37 (2000) 371-378.

[49] Y. Wang, S. Sikora, H. Kim, B. Dubey, T. Townsend, Mobilization of iron and arsenic from soil by construction and demolition debris landfill leachate, Waste Manage., 32 (2012) 925-932.

[50] A.A. Ramezanianpour, V.M. Malhotra, Effect of curing on the compressive strength, resistance to chloride-ion penetration and porosity of concretes incorporating slag, fly ash or silica fume, Cement and Concrete Composites, 17 (1995) 125-133. [51] H. Al-Khaiat, M.N. Haque, Effect of initial curing on early strength and physical properties of a lightweight concrete, Cem. Concr. Res., 28 (1998) 859-866.

[52] J. Bai, S. Wild, B.B. Sabir, Sorptivity and strength of air-cured and water-cured PC-PFAMK concrete and the influence of binder composition on carbonation depth, Cem. Concr. Res., 32 (2002) 1813-1821.

[53] C. Jing, S. Liu, X. Meng, Arsenic leachability and speciation in cement immobilized water treatment sludge, Chemosphere, 59 (2005) 1241-1247.

[54] S. Nakwanit, P. Visoottiviseth, S. Khokiattiwong, W. Sangchoom, Management of arsenic-accumulated waste from constructed wetland treatment of mountain tap-water, J. Hazard. Mater., 185 (2011) 1081-1085.

[55] K.S.B. Kameswari, A.G. Bhole, R. Paramasivam, Evaluation of Solidification/Stabilization (S/S) Process for the Disposal of Arsenic-Bearing Sludges in Landfill Sites, Environ. Eng. Sci., 18 (2001) 167-176. 
[56] F. Bardelli, M. Benvenuti, P. Costagliola, F. Di Benedetto, P. Lattanzi, C. Meneghini, M. Romanelli, L. Valenzano, Arsenic uptake by natural calcite: An XAS study, Geochim. Cosmochim. Acta, 75 (2011) 3011-3023.

[57] G.T. Schmidt, K.H. Lui, M. Kersten, Speciation and Mobility of Arsenic in Agricultural Lime, J. Environ. Qual., 38 (2009) 2058-2069.

[58] P. Costagliola, F. Bardelli, M. Benvenuti, F. Di Benedetto, P. Lattanzi, M. Romanelli, M. Paolieri, V. Rimondi, G. Vaggelli, Arsenic-Bearing Calcite in Natural Travertines: Evidence from Sequential Extraction, $\mu X A S$, and $\mu$ XRF, Environ. Sci. Technol., 47 (2013) 6231-6238. [59] L.H.E. Winkel, B. Casentini, F. Bardelli, A. Voegelin, N.P. Nikolaidis, L. Charlet, Speciation of arsenic in Greek travertines: Co-precipitation of arsenate with calcite, Geochim. Cosmochim. Acta, 106 (2013) 99-110.

[60] A.M. Scheidegger, M. Vespa, D. Grolimund, E. Wieland, M. Harfouche, I. Bonhoure, R. Dähn, The use of (micro)-X-ray absorption spectroscopy in cement research, Waste Manage., 26 (2006) 699-705.

[61] M.C. Schlegel, U. Mueller, U. Panne, F. Emmerling, Deciphering the Sulfate Attack of Cementitious Materials by High-Resolution Micro-X-ray Diffraction, Analytical Chemistry, 83 (2011) 3744-3749.

[62] B.Z. Dilnesa, E. Wieland, B. Lothenbach, R. Dähn, K.L. Scrivener, Fe-containing phases in hydrated cements, Cem. Concr. Res., 58 (2014) 45-55. 

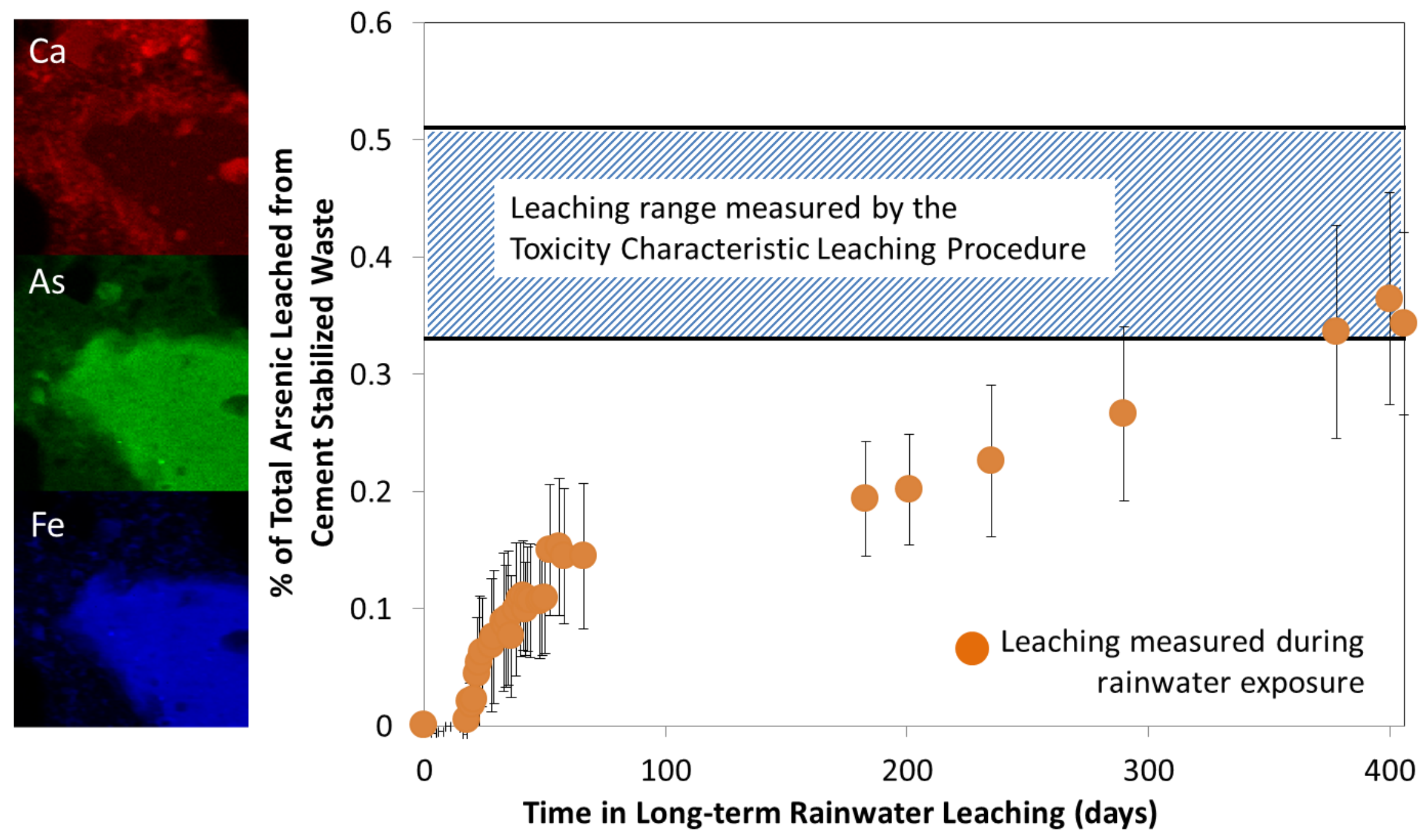